\title{
Gold Alloys for Porcelain-Fused-to-Metal Dental Restorations
}

\section{THEIR HARDENING BY ORDERING OF AN FEPt-TYPE COMPOUND}

\section{Randall M. German}

The J. M. Ney Co., Bloomfield, CT., U.S.A.*

\begin{abstract}
The age-hardenable dental alloys that have been developed specifically for use with porcelain veneers rely on high gold contents to ensure biocompatibility and on palladium and platinum additions to raise their melting range. Base metals such as iron, cobalt, nickel and copper are used to promote hardness and to give these alloys an age hardening potential. This study shows that age hardening results from the ordering of an FePt-type compound, a reaction which is insensitive to variations in porcelain firing cycles.
\end{abstract}

In restorative dentistry, aesthetic considerations have led to the development of the ceramo-metal prosthesis which consists of a cast metal substructure with a fused coating of dental porcelain matched in colour to natural dentition (Figure 1). Such restorations are individually fabricated after tooth preparation. The metal substructure is produced by the investment casting technique and is subsequently covered with dental porcelain fired onto the metal at approximately $1000^{\circ} \mathrm{C}$.

As with all dental materials, the primary criterion for alloy selection is that of long-term biocompatibility. In general, the biocompatibility of a dental alloy can be ensured through the use of a high noble metal content (gold + platinum group metals). Pure gold is inherently soft and, for this reason, harder gold-based alloys are used in most instances of prolonged contact with living tissue in the human mouth. The alloys employed as substrates for dental porcelain must be particularly hard to withstand mastication stresses, since deformation of its support will invariably lead to failure of the brittle porcelain.

*'The author is now with the School of Engineering, Rensselaer Polytechnic Institute, Troy, N.Y., U.S.A.

Fig. 1 A porcelain-fused-to-metal dental restoration. Each such appliance is individually falbricated for fit, occlusion and colour. The substrate metal is a gold-based special alloy. Once the restoration has been adjusted into place in the patient's mouth, the metallic surfaces are not visible
They must also be resistant to sagging during porcelain firing at $1000^{\circ} \mathrm{C}$ and their coefficients of thermal expansion must be compatible with those of the porcelains with which they are used. These latter requirements are particularly important because successive layers of porcelain. may be applied to the gold alloy substrate with consequent repeated firing.

The above criteria are satisfied in several commercial alloys with gold contents ranging from 75 to 88 per cent and total noble metal contents of 89 to 99 per cent. Both platinum and palladium additions are important in raising the melting range of such alloys, but hardness is achieved primarily through the addition of iron, cobalt, nickel or copper. Other alloying

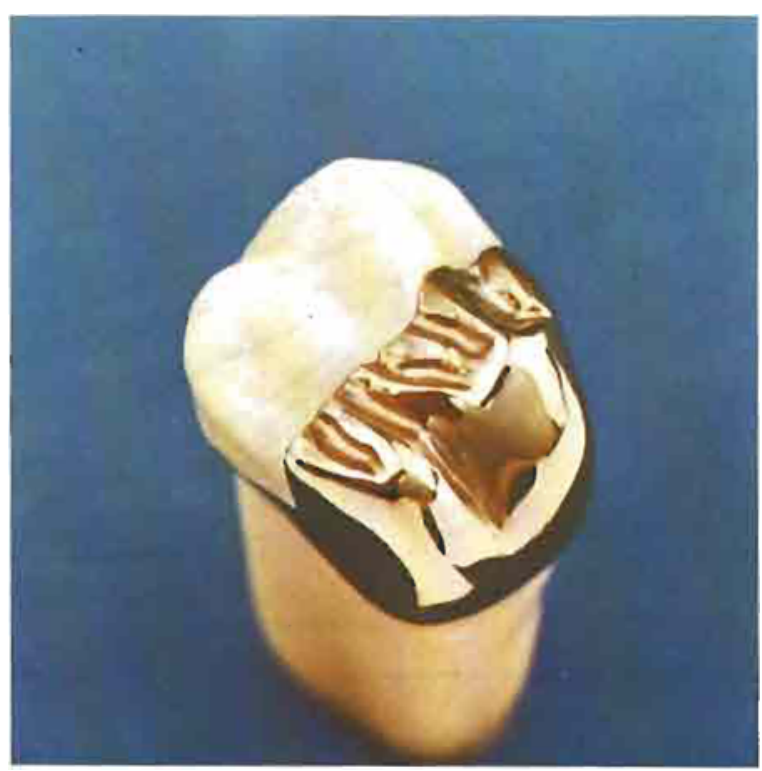


Table I

Hardness and Tensile Properties After Various Heat Treatments of a Dental Gold Alloy Containing Platinum, Iron and Cobalt

\begin{tabular}{|c|c|c|c|c|c|}
\hline \multirow[b]{2}{*}{ Condition } & \multirow[b]{2}{*}{$\begin{array}{c}\text { Hardness } \\
H^{H R_{B}}\end{array}$} & \multicolumn{4}{|c|}{ Tensile properties } \\
\hline & & $\begin{array}{c}\text { yield strength } \\
0.1 \% \text { offset, } \\
\mathrm{MPa}\end{array}$ & $\begin{array}{l}\text { ultimate tensile } \\
\text { strength, } \\
\mathrm{MPa}\end{array}$ & $\begin{array}{c}\text { elongation, } \\
\%\end{array}$ & $\begin{array}{l}\text { reduction in } \\
\text { area, } \\
\%\end{array}$ \\
\hline As-cast & 71 & 255 & 436 & 11 & 19 \\
\hline Solid solution & 55 & 171 & 352 & 30 & 36 \\
\hline $\begin{array}{l}\text { After porcelain } \\
\text { firing cycle }\end{array}$ & 94 & 427 & 558 & 15 & 25 \\
\hline $\begin{array}{l}\text { Solid solution } \\
\text { aged } 32 \text { minutes } \\
\text { at } 500^{\circ} \mathrm{C}\end{array}$ & 97 & 410 & 559 & 11 & 12 \\
\hline $\begin{array}{l}\text { Solid solution } \\
\text { aged } 8 \text { minutes } \\
\text { at } 600^{\circ} \mathrm{C}\end{array}$ & 97 & 396 & 587 & 10 & 14 \\
\hline $\begin{array}{l}\text { Solid solution } \\
\text { aged } 4 \text { minutes } \\
\text { at } 700^{\circ} \mathrm{C}\end{array}$ & 94 & 359 & 481 & 8 & 12 \\
\hline
\end{tabular}

additions include silver for the control of castability and colour, and 'oxide-formers' (gallium, zinc, indium or tin) to promote bonding to the porcelain.

Previous studies on gold alloys for ceramo-metal dental restorations have attempted to isolate the specific mechanisms whereby additions of a base metal such as iron promote hardness. O'Brien $e t$ al. showed (1) that iron-containing gold alloys are amenable to age hardening. Subsequent studies provided evidence that the hardening reaction is dependent on the presence of both platinum and iron $(2,3)$. Apparently, platinum-iron intermetallic phases dominate the hardening process, but there are still uncertainties as to the specific compound involved and the hardening mechanism. Thus, discontinuous precipitation at grain boundaries and compound ordering or decomposition reactions have been put forward as possibilities.
The present study was undertaken to eliminate these uncertainties regarding the identity of the hardening phase and the hardening mechanism. Specific attention has been given to the evolution of hardness during the dental porcelain firing cycle. The results provide a basis for advanced alloy design aimed at making the final alloy hardness insensitive to variations in the porcelain firing schedule.

\section{Experimental Approach}

A commercial dental gold alloy for ceramo-metal restorations was selected for this investigation (4). Similarities between this and other gold alloys for the same application suggested that results obtained with it could be applicable to the latter. The alloy is based on an 85 gold $/ 5$ platinum $/ 5$ palladium weight per cent matrix. As with many alloys of this type, other constituents include silver for castability and

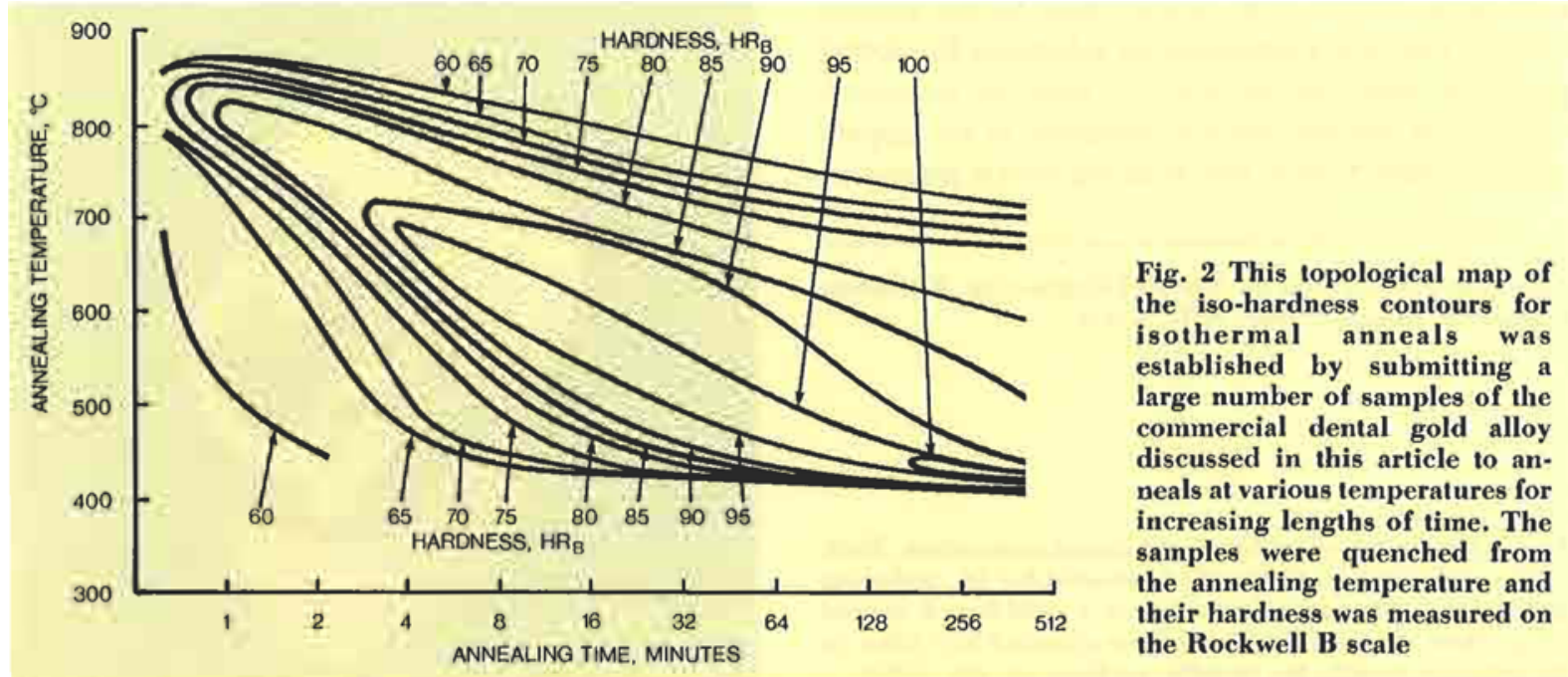


colour control, tin for hardening and oxide-bonding, as well as iron and cobalt for hardening. A number of standard experimental techniques was applied, including X-ray diffraction, dilatometry, optical metallography, scanning electron microscopy and microprobe energy dispersive $\mathrm{X}$-ray analysis.

The X-ray diffraction experiments were conducted using the $\operatorname{CuK} \alpha$ radiation filtered with nickel foil. High temperature resistivity measurements were taken at $2 \mathrm{~A}$ on strips $0.3 \times 5 \times 65 \mathrm{~mm}$ with spotwelded resistance probes of the same alloy. The tensile properties were measured on cylindrical specimens $3.1 \mathrm{~mm}$ in diameter with $12.7 \mathrm{~mm}$ gauge length. All hardness measurements were made using the Rockwell B scale. For the sake of brevity, a more complete description of the experimental approach will be avoided since standard instrumentation and techniques were used.

\section{Results}

Earlier experiments by the author have established that the quaternary gold-platinum-palladium-silver matrix of the alloy studied here has a very low hardness. In the complex commercial alloy, the hardening additions improve the as-cast hardness to $\mathrm{HR}_{\mathrm{B}} 71$. Following a typical porcelain firing cycle - heating from 650 to $980^{\circ} \mathrm{C}$ at $55^{\circ} \mathrm{C} /$ minute, holding at $980^{\circ} \mathrm{C}$ for 2 minutes, air cooling, repeated twice the alloy hardness improves to $\mathrm{HR}_{B} 94$, which is indicative of an ageing reaction. However, the details of such a firing cycle are determined by the specific porcelain and cannot be adjusted freely so as to optimize the age hardening process.

As is usual in investigations of this type, hardness measurements were used to monitor ageing and to characterize the phenomenon in greater detail. Initial$\mathrm{ly}$, it was established that an anneal at $1000^{\circ} \mathrm{C}$ for 30 minutes followed by quenching in water, resulted in a product of hardness $\mathrm{HR}_{\mathrm{B}} 55$ with a solid solution structure. Isothermal ageing treatments were then conducted between 450 and $800^{\circ} \mathrm{C}$ for times ranging fom 1 to 512 minutes. The resulting hardness changes were used to plot a topological hardness map (Figure 2) for the various ageing times and temperatures. As this map shows, isothermal ageing produces a hardness peak, the height of which increases with lower ageing temperatures. Clearly, overageing is a distinct possibility with the mechanism operative in the alloy. Table I gives some actual hardness values and mechanical properties measured in the ageing study. These data show that ageing under various conditions to a hardness peak results in increased tensile strength but reduced ductility. They also reveal similarities in properties between the isothermally aged specimens and those subjected to the porcelain firing cycle. Figure 3 shows how the hardness of the alloy develops during cooling from the porcelain firing temperature. The hardness climbs rapidly when the temperature drops below $850^{\circ} \mathrm{C}$. This result suggests that the ageing process is not dependent on diffusion.

Metallographic examination of the alloy in several conditions, including the annealed and quenched form, showed the presence of second phase particles. The scanning electron micrograph of Figure 4 illustrates the finely dispersed morphology of this second phase. Energy dispersive X-ray analysis revealed that the second phase particles are essentially platinum-iron intermetallics containing minor concentrations of cobalt. Figure 5 presents a secondary electron image with the corresponding line profile analyses for cobalt, iron and platinum. The fact that second phase particles were found in all samples of the alloy, irrespective of heat treatment, weighs against a precipitation reaction as the cause of age hardening. Semi-quantitative analysis results demonstrated that the particles of the second phase had the composition $\mathrm{PtFe}_{0.6} \mathrm{Co}_{0.3}$ with a \pm 0.1 standard error in respect of each constituent.

$\mathrm{X}$-ray diffraction was used to identify the structure of the alloy matrix as being face-centred cubic (f.c.c.) with a lattice parameter of $0,405 \mathrm{~nm}$. The second phase, constituting 3 per cent by volume of the alloy, was tentatively indexed as either f.c.c. or face-centred tetragonal (f.c.t.) with a parameter of $0.447 \mathrm{~nm}$.

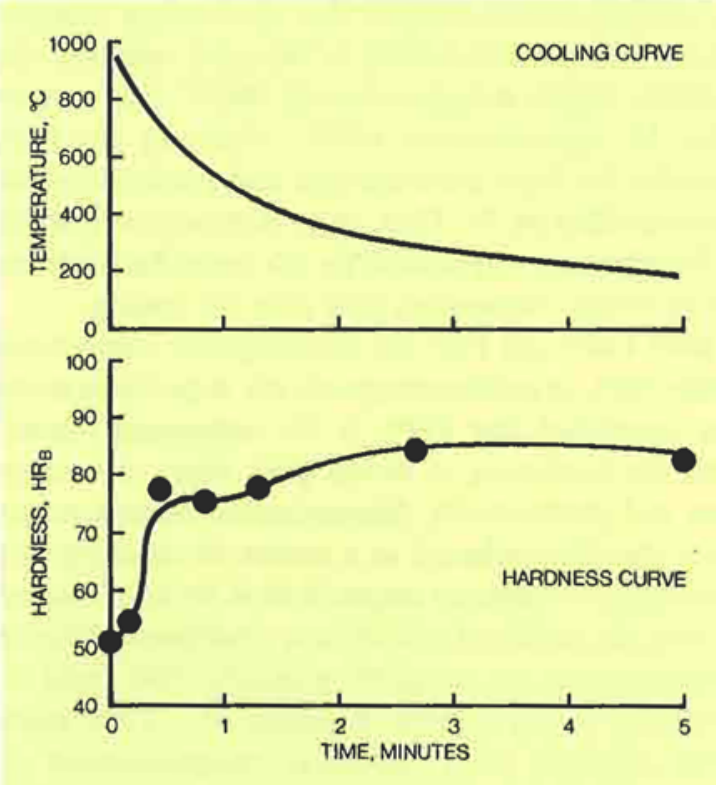

Fig. 3 Hardness development during cooling from the porcelain firing temperature of the ceramometal alloy discussed here. The top curve shows the cooling pattern while the bottom curve gives hardness values measured on specimens quenched after cooling times of up to 5 minutes. The final value for samples air-cooled to room temperature was $\mathbf{H R}_{\mathbf{B}} \mathbf{9 4}$ 


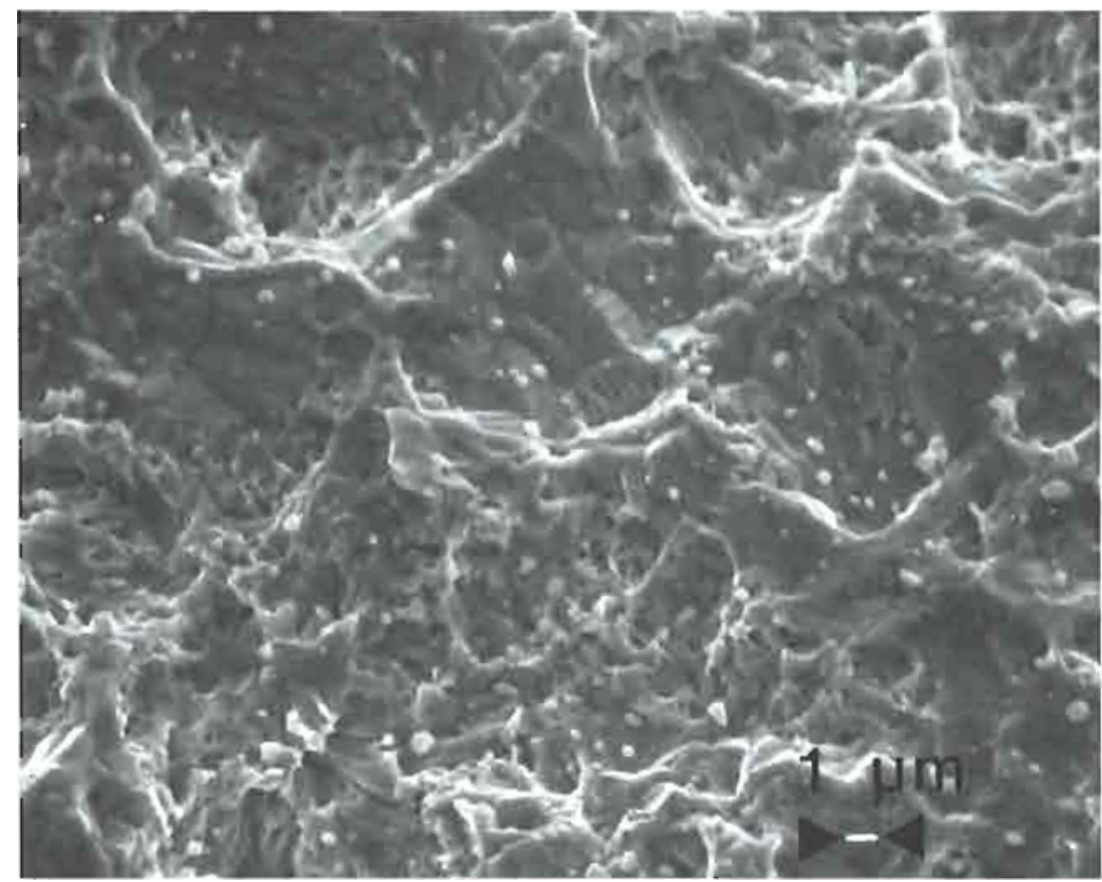

liig. 4 This scanning electron nicrograph of an etched specimen of a ceramo-netal dental gold alloy containing platinum and iron clearly shows fincly dispersed second phase particles

These latter data do not match those of any compound currently listed in the Powder Diffraction File, but they are thought to correspond to those of the $\mathrm{PtFe}_{0.0} \mathrm{Co}_{0.3}$ phase.

Electrical resistivity was measured using material in solid solution form and which was submitted to constant heating or cooling rates. Figure 6 gives the data on cooling, which indicate that an ordering reaction takes place (5). On cooling of the solid solution, the reaction begins at approximately $800^{\circ} \mathrm{C}$ and is complete by approximately $400^{\circ} \mathrm{C}$. Ordering has been reported for both platinum-iron and platinum-cobalt intermetallics $(6,7)$. Thus, there is strong evidence of ordering being responsible for the rapid hardness increase of the commercial gold alloy on cooling.

Both $\mathrm{CoPt}$ and $\mathrm{FePt}$ are ferromagnetic compounds while $\mathrm{FePt}_{3}$ is antiferromagnetic (6). A previous study has concluded that $\mathrm{FePt}_{3}$ is the compound responsible for hardening in dental gold alloys containing iron and platinum (3). Magnetization measurements were therefore selected as a means of checking this conclusion - induced magnetization being measured during the course of several heat treatments. Prior to magnetization, no remanent magnetic field could be measured in any sample. Exposure to a 2000 gauss field resulted in a remanent magnetization of $3.7 \pm 0.4$ gauss for material aged at $500^{\circ} \mathrm{C}$ for 32 minutes, which was at least three times the value measured on material in solid solution form. This result fails to support the earlier conclusion with respect to $\mathrm{FePt}_{3}$, but does support identification of the hardening phase as an equiatomic $\mathrm{Pt}(\mathrm{Fe}, \mathrm{Co})$ intermetallic compound.
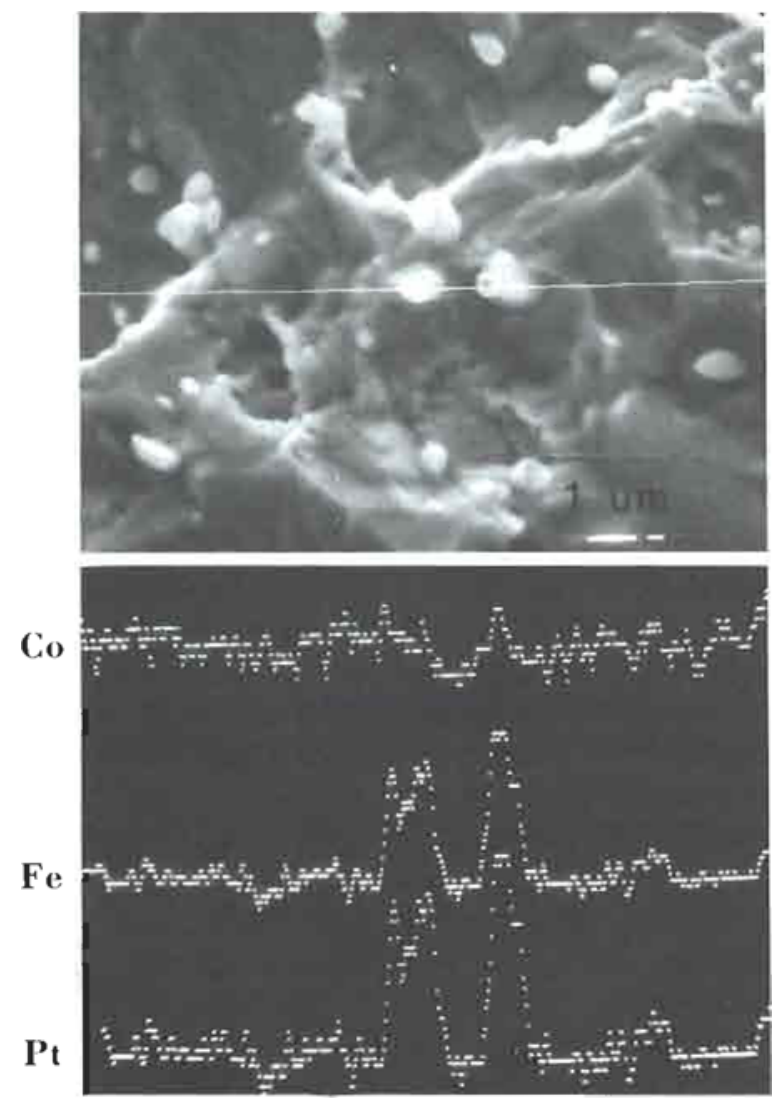

Fig. 5 Line profile concentration amalysis through particles of second phase in a ceramo-metal gold alloy containing platinum, iron and cobalt. The secondary clectron inage (top) indicates the position of the scan line, through two of the larger second phase particles. The concentration plots for platinum, iron and cohalt (bottom) reveal that the concentration of these elements is much higher in the sccond phase than in the surrounding matrix 


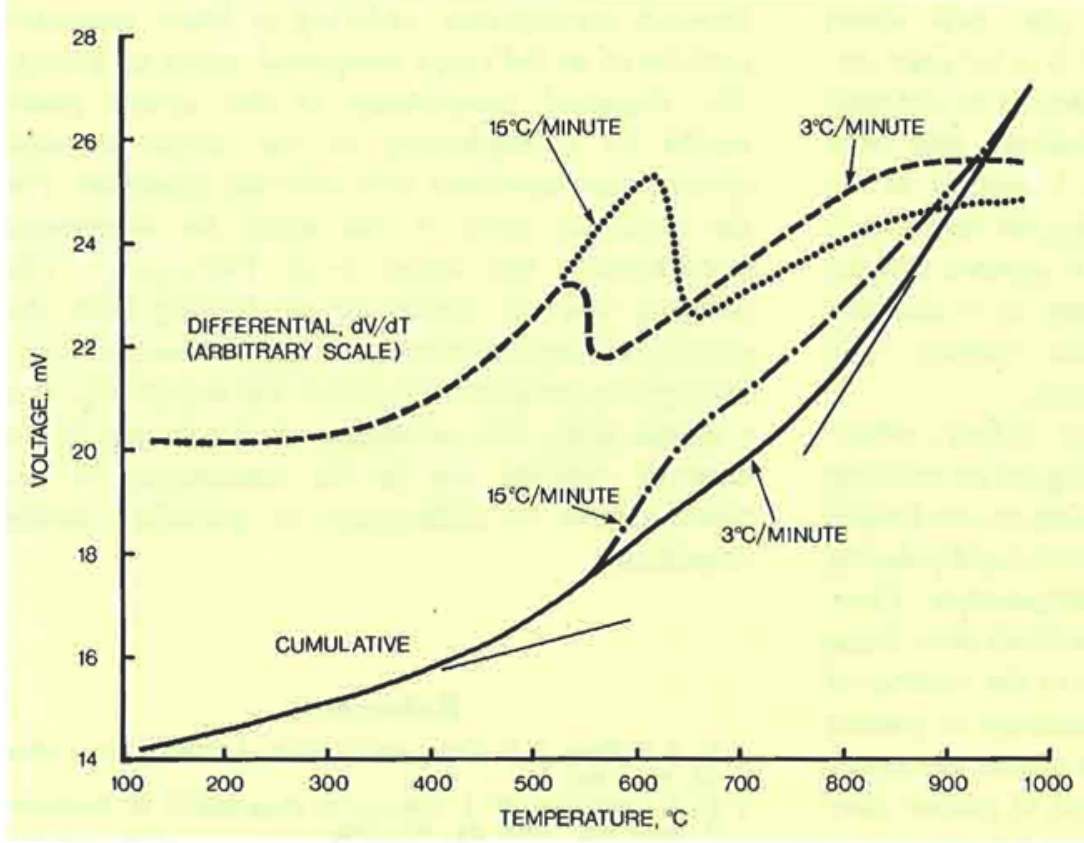

Fig. 6 Changes in resistivity of the dental gold alloy selected for this investigation, as reflected by the voltages required to maintain a constant current of 2 A through samples during cooling. Two rates of cooling from the firing temperature were used, namely 3 and $15^{\circ} \mathrm{C} /$ minute. The cumulative curves (bottom) correspond to the classic behaviour associated with ordering reactions. The differential curves (top) reveal that the rate of ordering is sensitive to the cooling rate

Finally, differential dilatometry experiments were performed against pure gold. With starting material in the annealed form, the experiments showed a nonlinear thermal expansion on heating, which is indicative of a volume dilatation. The volume dilatation reached a maximum at approximately $400^{\circ} \mathrm{C}$ and is interpreted as resulting from the lattice strains arising during the ordering reaction. It is probably these strains which give rise to the increased hardness.

\section{Discussion}

Data on the temperature dependence of hardness can be used to calculate an apparent activation energy for the ageing process in the alloy discussed here (Figure 7). The low value obtained, $75 \mathrm{~kJ} / \mathrm{mol}$, indicates that ageing is not dependent on classical nucleation and growth processes. Coupled with the resistivity and magnetization results, this provides additional support for the present conclusion that hardening in gold-based ceramo-metal dental alloys containing both iron and platinum occurs by ordering of a second phase.

On cooling from the porcelain firing temperature, ordering begins at approximately $850^{\circ} \mathrm{C}$. Both $\mathrm{CoPt}$ and $\mathrm{FePt}$ have critical transformation temperatures in this same range, giving ferromagnetic, f.c.t. ordered compounds $(6,7)$. The formulation $\mathrm{PtFe}_{\mathfrak{0} .6} \mathrm{Co}_{0.3}$, as determined for the second phase, is thermodynamically possible in the light of available binary data and a compound of this composition would be expected to have a high formation temperature, wide compositional range, high stability and a f.c.t. structure, isotypic with that of $\mathrm{AuCu}$ in the ordered condition (8).
An important result of this study is that both the hardening compound and hardening mechanism have been identified for the class of dental gold alloys containing iron and platinum. Previous conclusions $(1,2$, 3) were that hardening resulted from a precipitation reaction involving the formation of $\mathrm{FePt}_{3}$. They were not based, however, on any direct evidence for the formation or precipitation of this compound. The present investigation shows that hardening is not due to precipitation, but to ordering based on the equiatomic $\mathrm{Pt}(\mathrm{Fe}, \mathrm{Co})$ compound. An examination of other dental

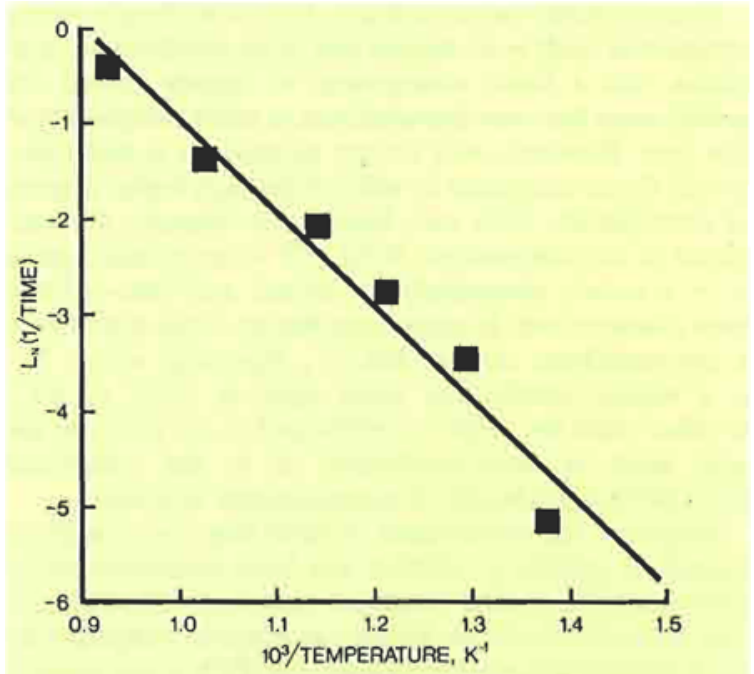

Fig. 7 An Arrhenius plot of the inverse time to peak hardness against the inverse ageing temperature for the dental gold alloy studied in this article. The data show ageing to be a thermally activated process with an apparent activation energy of $75 \mathrm{~kJ} / \mathrm{mol}$ 
alloys containing 81 to 87 per cent gold shows evidence of ordering reactions and it is virtually certain therefore that their hardening occurs by the same mechanism. Such studies also indicate that both palladium and tin can constitute a portion of the hardening second phase, depending on the iron to platinum content ratio. However, it appears that the best properties result from the use of a hardener (iron + cobalt + nickel) to platinum content ratio which is near unity on an atomic basis.

For dental applications there are definite advantages associated with alloy hardening by an ordering reaction. Since the kinetics of ordering are not limited by rates of diffusion, hardening occurs rapidly during cooling from the porcelain firing temperature. Thus, near-optimal hardness is obtained without there being any need to give specific attention to the number of firing cycles, porcelain firing temperature or cooling rate. The dental practitioners and dental laboratory technicians can therefore be assured of proper alloy hardness irrespective of the porcelain firing schedule which they use.

\section{Conclusions}

The reaction kinetics of age hardening in a high gold content ceramo-metal alloy have been examined in detail. Hardening has been shown to result from an ordering reaction with consequent rapid hardness increases during cooling from the porcelain firing temperature. It has also been shown that, contrary to previous assumptions, ordering of finely dispersed particles of an FePt-type compound causes hardening. The dispersed morphology of this second phase results in strengthening of the lattice through microstrains associated with ordering dilatation. For the particular alloy of this study the compound stoichiometry was found to be $\mathrm{PtFe}_{0.6} \mathrm{Co}_{0.3}$. The ordering reaction begins on air cooling from the porcelain firing temperature at approximately $850^{\circ} \mathrm{C}$ and reaches completion between 400 and $250^{\circ} \mathrm{C}$. For a dental alloy, the advantage of hardening by an ordering reaction lies in the insensitivity of the phenomenon to differences in porcelain firing schedules.

\section{References}

1 W. J. O'Brien, J. E. Kring and G. Ryge, f. Prosth. Dent., 1964, 14, $955-960$

2 K. F. Leinfelder, W. J. O'Brien, G. Ryge and C. W. Fairhurst, f. Dent. Res., 1966, 45, 392-396

3 D. L. Smith, A. P. Burnett, M. S. Brooks and D. H. Anthony, 7. Dent. Res., 1970, 49, 283-288

4 IMage, Patent Pending, The J. M. Ney Co., Bloomfield, CT., U.S.A.

5 G. V. Raynor in 'Physical Metallurgy', edited by R. W. Cahn, North-Holland, Amsterdam, 1965, pp. 291-363

$6 \mathrm{~J}$. S. Kouvel in 'Intermetallic Compounds', edited by J. H. Westbrook, John Wiley \& Sons, New York, 1967, pp, 529-568

7 W. B. Pearson, 'A Handbook for Lattice Spacings and Structures of Metals and Alloys', Pergamon Press, London, 1967

8 R. Hultgren, P. D. Desai, D. T. Hawkins, M. Gleiser and K. K. Kelley, 'Selected Values of the Thermodynamic Properties of Binary Alloys', American Society for Metals, Metals Park, OH., 1973

\section{The Stereochemistry of Gold(I) Complexes}

Gold is usually two-coordinate, both in its simple binary compounds such as its halides and in its coordination complexes, and a linear arrangement of ligands around the gold(I) atom has been demonstrated in many compounds of this type. However, with tertiary phosphines in particular, gold(I) forms complexes in which it displays higher degrees of coordination. With such ligands, for example, 2:1 complexes of the composition $\mathrm{AuXL}_{2}$ (X = an anionic ligand, $\mathbf{L}=$ a tertiary phosphine) are formed and have recently been characterized. In some cases they are ionic and contain a two-coordinate cation $\left(\mathrm{AuL}_{2}\right)^{+}$, especially where $\mathrm{X}^{-}$ is a weakly coordinated anion such as $\mathrm{ClO}_{4}^{-}$or $\mathrm{PF}_{6}^{-}$. In other cases the anion is coordinated to the gold and the gold atom is three-coordinate, as in the compound $\left[\mathrm{AuCl}\left(\mathrm{PPh}_{3}\right)_{2}\right] \cdot 0.5 \mathrm{C}_{6} \mathrm{H}_{6}$ of trigonal-planar structure.

Moreover, the coordination of more than two phosphine ligands to gold(I) in solution has been demonstrated by phosphorus-31 nuclear magnetic resonance spectroscopy. The best defined of these higher coordination complexes are those formed with triphenylphosphine $\left(\mathrm{PPh}_{3}\right)$, and solids of composition $\left[\mathrm{Au}\left(\mathrm{PPh}_{3}\right)_{\mathrm{n}}\right] \mathrm{ClO}_{4}(\mathrm{n}=2,3$ or 4 ) have been isolated (1), though their precise structures have not been determined.

Structural diagnoses can be readily made on such solid materials by gold-197 Mössbauer spectroscopy, and R. V. Parish and J. D. Rush of the Department of Physics of the
University of Liverpool have recently (2) applied this technique in a study of these latter complexes. They found that the Mössbauer parameters of the complexes were extremely sensitive to the number and nature of the ligands attached to the gold.

In the case of the complex $\left[\mathrm{Au}\left(\mathrm{PPh}_{3}\right)_{2}\right] \mathrm{ClO}$, these parameters were consistent with a linear two-coordination of the gold. A zero quadrupole splitting unambiguously confirmed a tetrahedral four-coordination for the cation in $\left[\mathrm{Au}\left(\mathrm{PPh}_{3}\right)_{4}\right] \mathrm{ClO}_{4}$. (With a d ${ }^{10}$ ion, the electric field gradient is determined entirely by the distribution of the ligands and is therefore zero for a tetrahedral configuration). The complex $\left[\mathrm{Au}\left(\mathrm{PPh}_{3}\right)_{3} \mathrm{CClO}_{4}\right.$ must involve trigonal threecoordination and the Mössbauer parameters were indeed consistent with its geometry being trigonal-planar.

Although these findings are not unexpected, they constitute a significant addition to our knowledge of complex formation by monovalent gold.

\section{References}

1 L. Malatesta, L. Naldini, G. Simonetta and F. Cariati, Coord. Chem. Rev., 1966, 1, 255-262

2 R. V. Parish and J. D. Rush, Chem. Phys. Lett., 1979, 63, (1), 37.39 